\title{
Eco-Friendly green liquid chromatographic for determination of Doxycycline in tablets and in the presence of its degradation products
}

\author{
Loren Fernanda Ghidini ${ }^{\mathrm{a}}$, Ana Carolina Kogawa*a and Hérida Regina Nunes Salgado ${ }^{\mathrm{a}}$
}

${ }^{a}$ São Paulo State University (UNESP), School of Pharmaceutical Sciences, Campus Araraquara, São Paulo, Brazil

*Corresponding author:ac_kogawa@yahoo.com.br

Doxycycline, an oral antimicrobial, does not present a sustainable analytical method described in the literature using liquid chromatography. A new and efficient method was developed and validated for the quantification of doxycycline tablets by HPLCUV. Its aim is the contribution to the green analytical chemistry since it has low use of organic solvent and low production of toxic waste. The HPLC-UV method used a mixture of purified water $+0.5 \%$ acetic acid and ethanol (40:60, v/v). The flow rate was $0.8 \mathrm{~mL} \mathrm{~min}^{-1}, \mathrm{C} 18$ Luna column, $20 \mu \mathrm{L}$ of injected volumes at $275 \mathrm{~nm}$. The samples were prepared in purified water and the method was linear over the concentration range of $20-200 \mu \mathrm{gL} \mathrm{m}^{-1}(\mathrm{r}=0.9997)$ with limits of detection and quantification of 1.08 and $3.27 \mu \mathrm{g} \mathrm{mL}^{-1}$, respectively. The precision of the method showed RSD $0.50 \%$ (intra-assay), $2.35 \%$ (inter-assay) and $1.13 \%$ (between analysts). The accuracy of the method was determined by standard recovery and it was $99.85 \%$. The DOX tablets were subjected to oxidative, acid, basic, neutral and photolytic degradation and it showed be stability indicative. Statistical analysis provided reliable, safety and reproducible results. The method is considered linear, selective, precise, accurate, robust, indicative of stability and safe to be used in routine quality control analyzes for determination and quantification of doxycycline in tablets. The proposed method is an ecologically correct alternative for the evaluation of doxycycline tablets.

Keywords: doxycycline, tablets, green analytical chemistry, method validation.

\section{Introduction}

Doxycycline (DOX, Figure 1) is a second generation semisynthetic antibiotic of tetracycline family (1). DOX is an antibiotic used for treatments of diseases caused by anaerobic and aerobic bacteria (2) as well as Gram-negative and Gram-positive bacteria (3). DOX is preferentially chosen when compared to the other tetracycline in specific infections due to the high absorption and its long half-life. This allows a lower dosage frequency (4) and to have a better clinical efficacy in low concentrations, such as between 2 or 4 times the level of minimal of inhibition concentration (MIC) for susceptible microorganisms (5). The high performance liquid chromatography (HPLC) is an analytical technique widely used in analytical laboratories of chemical and pharmaceutical industries for routine analysis of quality control (6-7). Among the techniques used in quality control, HPLC is a technique with major advantages since it provides faster analysis, better resolution, greater sensitivity, detectability and precision (8).<smiles>C[C@H]1c2cccc(O)c2C(=O)C2=C(O)[C@]3(O)C(=O)C(C(N)=O)=C(O)[C@@H](N(C)C)[C@H]3[C@H](O)[C@H]21</smiles>

Figure 1. Chemical structure of DOX (CAS 24390-14-5).
High performance liquid chromatography has been used to determine doxycycline in biological fluids, serum, blood or urine (9), and mainly in pharmaceutical products as tablets (10) and capsules (11-12). However, the most methods using HPLC to determine DOX use of toxic solvents as acetonitrile, methanol or oxalic acid $(9,13)$, which when compounded compromise the health of operators, and in addition, if discarded incorrectly, to the environment (1416). Therefore, it is necessary and important to use green analytical chemistry in the development of chemical techniques and methods that reduce or eliminate the use of solvents, reagents or the generation of toxic waste while maintaining accuracy, sensitivity and reproducibility of the analytical method for DOX quantification in tablets by HPLC.

The search for ecologically sustainable methodologies has been important in pharmaceutical industries, highlighting trends in eliminate the mobile phases composed of toxic organic solvents. This brings benefits not only for industries, as well as for operators and the environment (14-16). HPLC technique is expensive due to costs of equipment, accessories, reagents and personnel training (17) and the use of anti-toxic solvents reduce once environmental impacts will reduce toxic waste, develop simpler methods, reduce solvent elimination, lower production costs, lower equipment risks and longer shelf life of chromatographic columns (18). Besides that, ethanol is a biodegradable solvent, the environmental impacts are minimized and can be easily replaced and reused because it is the least toxic (19). Currently, the use of water and ethanol as mobile phase is already a reality; methods to determine drugs such as sodium cefepime hydrochloride (20), ceftriaxone sodium (21), cefadroxil (22), daptomycin (23), ampicillin (24), cefazolin sodium (25) aztreonam (26) and rifaximin (27) 
were developed and validated using green analytical chemistry.

In addition, DOX has highly solubility in water, which it was possible to prepare the samples in aqueous medium, further contributing to green analytical chemistry.

This paper describes the development and validation of high performance liquid chromatographic technique for the quantification of doxycycline in tablets using no toxic solvents, aiming to contribute to green analytical chemistry and to environment preservation and safety of operators. Moreover, the method shows reliable results that can be satisfactorily interpreted.

\section{Experimental}

\section{Reagents}

Materials and standards HPLC grade ethanol (Panreac $\AA$, Barcelona, Spain), HPLC grade acetic acid (J.T. Baker ${ }^{\circledR}$, Phillipsburg, NJ) were used. Deionized Milli Q water (Millipore ${ }^{\circledR}$, Bedford, MA) was used to prepare the mobile phase and diluent solutions. DOX standard and tablets were supplied by União Química Pharmaceutical (Pouso Alegre, Brazil).

\section{Equipment}

HPLC analysis was performed on a Waters ${ }^{\circledR}$ HPLC system equipped with a Waters 1525 binary gradient chromatography pump; a Rheodyne Breeze 7725i manual injector and a Waters 2487 ultraviolet-visible (UV-Vis) detector.

\section{Chromatographic conditions}

Chromatographic analysis was conducted at ambient temperature on a C18 Luna column (250 mm x $4.6 \mathrm{~mm}, 5.0$ $\mu \mathrm{m}$ particle size). The mobile phase was a mixture of purified water $+0.5 \%$ acetic acid and ethanol in the ratio 40:60 (v/v), and filtering through a $0.45 \mu \mathrm{m}$ membrane filter. A stock standard solution equivalent to $200 \mu \mathrm{g} \mathrm{mL} \mathrm{m}^{-1} \mathrm{DOX}$ was prepared by dissolving an accurately weighed amount of pure drug in the diluent solution. The flow rate was 0.8

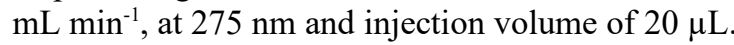

\section{Pharmaceutical preparations}

Twenty tablets were accurately weighed, crushed into a fine powder and mixed using a mortar and pestle. A quantity of tablet powder equivalent to $80 \mathrm{mg}$ of DOX was weighed accurately into a $25 \mathrm{~mL}$ calibrated flask; the diluent solution was added and the mixture was sonicated for $5 \mathrm{~min}$ to complete dissolution of the DOX; the mixture was then diluted to the mark with the diluent. A small portion of the resulting mixture was withdrawn and filtered through a 0.45 $\mu \mathrm{m}$ filter to ensure the absence of particulate matter. The filtrate was appropriately diluted with the diluent before injection onto the column.

\section{Method}

Method validation was performed according to the parameters established in international guidelines (28-33) for linearity, selectivity, accuracy, precision, robustness, detection limit and quantitation limit.

\section{Linearity}

Linearity was evaluated by regression analysis. $20 \mu \mathrm{L}$ of standard solutions (20-200 $\left.\mu \mathrm{g} \mathrm{mL}^{-1} \mathrm{DOX}\right)$ were injected onto the column in triplicate and the chromatograms were recorded. The equation of the line was determined by linear regression analysis by the method of least squares. The peak height used in determining the calibration curve was statistically evaluated by Analysis of Variance (ANOVA).

\section{Wavelength selection, Specificity and Identification of the peak}

The wavelength for determination of peaks was performed by scanning the standard, vanillin, in the range from $190 \mathrm{~nm}$ to $400 \mathrm{~nm}$. The analysis of the spectrum was used to confirm the identity of each compound of interest. Additionally, scans from $190 \mathrm{~nm}$ to $400 \mathrm{~nm}$ were performed for the extract solution from the herbal material, tincture and for the spiked extractive solution and tincture with the standard (vanillin) in order to verify the occurrence of deviation from the maximum wavelength. Therefore, the peak in the samples were identified by comparing their retention time and area with the standard.

\section{Precision}

The precision of the method was performed through three aspects: intra-assay (repeatability), inter-assay and between analysts (intermediate precision). Intra-assay precision was performed by the preparation and analysis of six injections of DOX at the concentration of $60 \mu \mathrm{g} \mathrm{mL}^{-1}$, on the same day, same analyst and in the same working conditions, analyzing the RSD (\%) among such determinations. The precision inter-assay was performed by the preparation of six injections of DOX in concentration of $60 \mu \mathrm{g} \mathrm{mL}^{-1}$, in three different days, same analyst and in the same working conditions, and about between analysts, the precision was performed by the preparation of six injections of DOX in concentration of $60 \mu \mathrm{g} \mathrm{mL}^{-1}$, in two different days, different analysts and in the same working conditions. The results were analyzed by RSD (\%).

\section{Accuracy}

The accuracy of the method was determined by measuring the reference standard recovery in triplicate at three levels from 80 to $120 \%$ of the method concentration $\left(60 \mu \mathrm{g} \mathrm{mL} \mathrm{m}^{-1}\right)$, according to ICH recommendations (28). A standard solution containing $200 \mu \mathrm{g} \mathrm{mL}^{-1}$ of DOX was prepared using 
Drug Anal Res, 2017; 02, 49-55

deionized Milli $\mathrm{Q}$ water. In volumetric flasks of $5 \mathrm{~mL}$, aliquots of 700,1000 and $1300 \mu \mathrm{L}$ of this standard solution were individually added to $500 \mu \mathrm{L}$ of sample solutions at $200 \mu \mathrm{g} \mathrm{mL}^{-1}$. The final concentrations were 48,60 and $72 \mu \mathrm{g}$ $\mathrm{mL}^{-1}$, which correspond to 80,100 and $120 \%$ of the target concentration, respectively. Mean recovery and RSD (\%) were calculated. The preparations are shown in Table 1. The recovery percentage $(\mathrm{R} \%)$ was calculated using the Equation 1, which is determined by Association of Official Analytical Chemists (34).

Table 1. Preparation of the solutions of DOX for the recovery test of the high performance liquid chromatography method

\begin{tabular}{ccccc}
\hline & $\begin{array}{c}\text { DOX } \\
\text { sample } \\
(\boldsymbol{\mu L})^{\mathbf{a}}\end{array}$ & $\begin{array}{c}\text { DOX } \\
\text { standard } \\
(\boldsymbol{\mu L})^{\mathbf{a}}\end{array}$ & $\begin{array}{c}\text { Final theoretical } \\
\text { concentration }(\boldsymbol{\mu g} / \\
\mathbf{m L})^{\mathbf{b}}\end{array}$ & $\begin{array}{c}\text { Level } \\
(\%)\end{array}$ \\
\hline $\mathbf{R}$ & 500 & 700 & 48 & 80 \\
$\mathbf{1}$ & & & 60 & 100 \\
$\mathbf{R}$ & 500 & 1000 & 72 & 120 \\
$\mathbf{2}$ & & 1300 & & \\
$\mathbf{R}$ & 500 & $\mathbf{3}$ & & \\
$\mathbf{3}$ & & & 72 & \\
\hline
\end{tabular}

a -Volumetric flask of $5 \mathrm{~mL}$; b - Concentration levels prepared in triplicate

Equation 1: $\mathbf{R} \%=\{(\mathrm{Cr}-\mathrm{Ca}) / \mathrm{Cp}\} \times 100$

Where:

$\mathrm{Cr}=$ Concentration of the standard added sample $\left(\mu \mathrm{g} \mathrm{mL}^{-1}\right)$

$\mathrm{Ca}=$ Concentration of the sample $\left(\mu \mathrm{g} \mathrm{mL}^{-1}\right)$

$\mathrm{Cp}=$ Theoretical concentration of standard DOX added $(\mu \mathrm{g}$ $\mathrm{mL}^{-1}$ )

\section{Selectivity}

Selectivity was evaluated by forced degradation procedure (35). DOX samples solutions were prepared in $0.1 \mathrm{~mol} \mathrm{~L}^{-1}$ $\mathrm{HCl}, \quad 0.1 \mathrm{~mol} \mathrm{~L} \mathrm{~L}^{-1} \mathrm{NaOH}, \quad 3 \% \quad \mathrm{H}_{2} \mathrm{O}_{2}$ and $\mathrm{H}_{2} \mathrm{O}$ at a

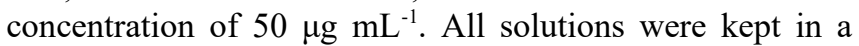
water bath at $60{ }^{\circ} \mathrm{C}$. Aliquots of these solutions were taken at 1, 3 and 6 hours and analyzed immediately by the HPLC method. Additionally, a solution of DOX was prepared in water at a concentration of $50 \mu \mathrm{g} \mathrm{mL}^{-1}$ and submitted to UV light. Aliquots of this solution were taken at 1, 3 and 6 hours and analyzed immediately by the HPLC method. An overlap of chromatograms of DOX standard and sample was analyzed to prove the excipients do not influence the quantification.

\section{Robustness}

The robustness was evaluated using Youden \& Steiner (36) test. The solutions of of DOX tablets at $60 \mu \mathrm{g} \mathrm{mL}^{-1}$ were prepared and analyzed in each conditions. Table 2 shows the variations that were performed (upper case letters represent normal working conditions and lower case letters represent small changes).
Table 2. Combinations analyzed for the robustness evaluation of the high-performance liquid chromatography method by Youden and Steiner test.

Experiments

\begin{tabular}{|c|c|c|c|}
\hline Conditions & Normal & Changed & $\begin{array}{llllllll}1 & 2 & 3 & 4 & 5 & 6 & 7 & 8\end{array}$ \\
\hline $\begin{array}{l}\text { Wavelenght } \\
(\mathrm{nm})\end{array}$ & 275 & 276 & A A A A a a a \\
\hline $\begin{array}{l}\text { Ethanol } \\
\text { brand }\end{array}$ & Panreac ${ }^{\circledR}$ & J.T.Baker $^{\circledR}$ & $\mathrm{B} \quad \mathrm{B} \quad \mathrm{b} \quad \mathrm{B} \quad \mathrm{B} \quad \mathrm{B} \quad \mathrm{b} \quad \mathrm{b}$ \\
\hline$\%$ acetic acid & 0.5 & 0.6 & $\mathrm{C} \quad \mathrm{c} \quad \mathrm{C} \quad \mathrm{C} \quad \mathrm{C} \quad \mathrm{c} \quad \mathrm{C} c$ \\
\hline $\begin{array}{l}\text { Proportion of } \\
\text { etanol }\end{array}$ & 60 & 61 & $\mathrm{D} D \mathrm{~d} D \mathrm{D} d \mathrm{D}$ \\
\hline $\begin{array}{c}\text { Flow } \\
(\mathrm{mL} / \mathrm{min})\end{array}$ & 0.8 & 0.9 & $\mathrm{E} e \mathrm{E} E \mathrm{E}$ e $\mathrm{E}$ \\
\hline $\begin{array}{c}\text { Injection } \\
\text { volume }(\mu \mathrm{L})\end{array}$ & 20 & 21 & $F \quad f \quad f \quad F \quad F \quad f \quad f \quad F$ \\
\hline $\begin{array}{l}\text { Room } \\
\text { temperature } \\
\left({ }^{\circ} \mathrm{C}\right)\end{array}$ & 25 & 27 & $G g g G G G G$ \\
\hline
\end{tabular}

\section{Limits of detection and quantification}

The limit of detection (LOD) and limit of quantification (LOQ) of the method were obtained from Equations 2 and 3:

\section{Equation 2: LOD: $3.3 \sigma / \mathrm{S}$}

$$
\text { Equation 3: LOQ: } 10 \text { \%/S }
$$

Where:

$\sigma:$ Standard deviation of the response

S: Slope of the calibration curve

\section{Results}

\section{Linearity}

A standard solution of DOX $\left(200 \mu \mathrm{g} \quad \mathrm{mL}^{-1}\right)$ was appropriately diluted with the diluent solution to obtain solutions in the concentration range of $20-200 \mu \mathrm{g} \mathrm{mL}^{-1}$ DOX. Twenty microliters of each solution were injected in triplicate into the column under the previously described chromatographic conditions. Figure 2 and Table 3 show the results. 
Drug Anal Res, 2017; 02, 49-55

Table 3. Analysis of variance of the values obtained in the analytical curves of DOX using the high-performance liquid chromatography method

\begin{tabular}{cccccc}
\hline Source of variation & $\begin{array}{c}\text { Degree of } \\
\text { freedom }\end{array}$ & Sum of square & Variability & tcalculated & $\begin{array}{c}\mathbf{t}_{\text {critical }} \\
\mathbf{( 0 . 0 5 )}\end{array}$ \\
\hline Between concentrations & 5 & 772369508178 & 154473901635 & 311 & 3.11 \\
Linear regression & 1 & 771944437870 & 771944437870 & 1556 & 4.75 \\
Deviation of linearity & 4 & 425070307 & 106267576 & 0.21 & - \\
Residue & 12 & 496068171 & 41339014 & - \\
Total & 17 & 772865576349 & - & - \\
\hline
\end{tabular}

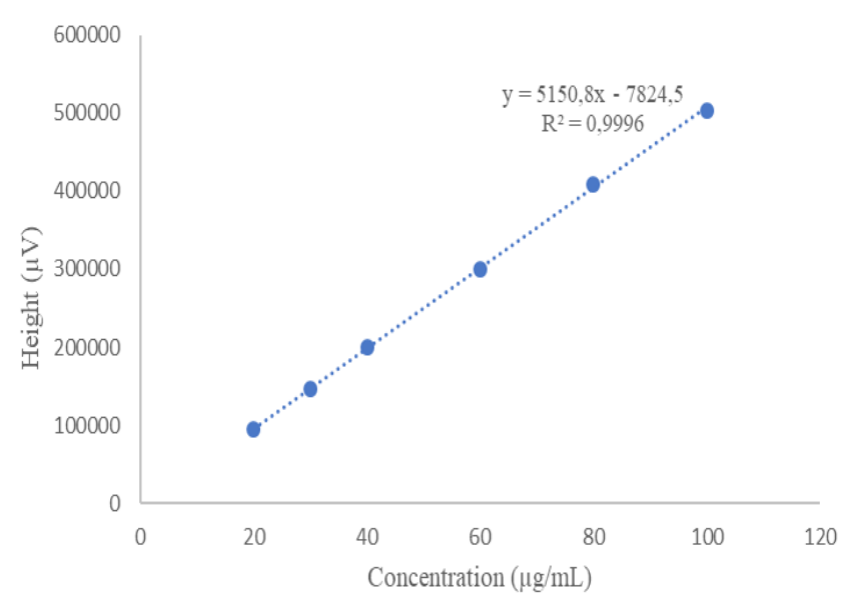

Figure 2. Analytical curve of DOX at concentrations of 20, $30,40,60,80,100$ and $200 \mu \mathrm{gL}^{-1}$ by HPLC method.

\section{Precision}

The precision of the method was obtained according to the following criteria: intra-assay (repeatability), inter-assay and between analysts' way (intermediate). The Table 4 show the results intra-assay, inter-assay and between two analysts, respectively.

Table 4. Determined values for precision intra-assay, inter-assay and between analysts by high performance liquid chromatography method

\begin{tabular}{|c|c|c|c|c|c|c|c|}
\hline \multirow[t]{2}{*}{ Intra-assay } & \multicolumn{6}{|c|}{ Peak height* } & \multirow[t]{2}{*}{$\begin{array}{r}\text { RSD } \\
(\%) \\
\end{array}$} \\
\hline & 1 & 2 & 3 & 4 & 5 & 6 & \\
\hline Day 1 & 291020 & 289664 & 301938 & 303978 & 301876 & 306768 & 0.50 \\
\hline Inter-assay & \multicolumn{6}{|c|}{ Peak height ${ }^{\mathrm{a} *}$} & $\begin{array}{l}\text { RSD } \\
(\%)\end{array}$ \\
\hline Day 1 & \multicolumn{6}{|c|}{294491} & \multirow{3}{*}{2.35} \\
\hline Day 2 & \multirow{2}{*}{\multicolumn{6}{|c|}{$\begin{array}{l}304033 \\
308362\end{array}$}} & \\
\hline Day 3 & & & & & & & \\
\hline $\begin{array}{l}\text { Between } \\
\text { analysts }\end{array}$ & \multicolumn{6}{|c|}{ Peak height* } & $\begin{array}{l}\text { RSD } \\
(\%)\end{array}$ \\
\hline & 1 & 2 & 3 & 4 & 5 & 6 & \\
\hline Analyst 1 & 291020 & 289664 & 301938 & 303978 & 301876 & 306768 & \multirow{2}{*}{1.13} \\
\hline Analyst 2 & 297992 & 307185 & 306713 & 303625 & 307060 & 301620 & \\
\hline
\end{tabular}

average peak height by six determinations

*Concentration solutions of $60 \mu \mathrm{g} \mathrm{mL}^{-1}$

\section{Accuracy}

The accuracy of the method was confirmed by determining the average recoveries from the samples by applying the standard addition method. The Table 5 shows the results.

Table 5. Values obtained in the DOX recovery test of the accuracy parameter by high performance liquid chromatography method

\begin{tabular}{cccccc}
\hline & $\begin{array}{c}\text { DOX } \\
\text { standard } \\
\text { added }(\boldsymbol{\mu g} / \\
\mathbf{m L})\end{array}$ & $\begin{array}{c}\text { DOX } \\
\text { standard } \\
\text { found } \\
(\boldsymbol{\mu g} / \mathbf{m L})\end{array}$ & $\begin{array}{c}\text { Recovery } \\
\mathbf{( \% )}\end{array}$ & $\begin{array}{c}\text { Average } \\
\text { Recovery } \\
\mathbf{( \% )}\end{array}$ & $\begin{array}{c}\text { RSD } \\
\mathbf{( \% )}\end{array}$ \\
\hline $\mathbf{R} 1$ & 28 & 28.25 & 100.89 & & \\
$\mathbf{R 2}$ & 40 & 40.47 & 101.18 & 99.85 & 0.38 \\
$\mathbf{R 3}$ & 52 & 51.15 & 98.36 & & \\
\hline
\end{tabular}


Robustness

The mean of variations in brand of ethanol, wavelength, percentage of acid acetic, proportion of ethanol, room temperature, flow and injection volume to evaluate the robustness parameter was statistically analyzed. The result is shown in Figure 3.

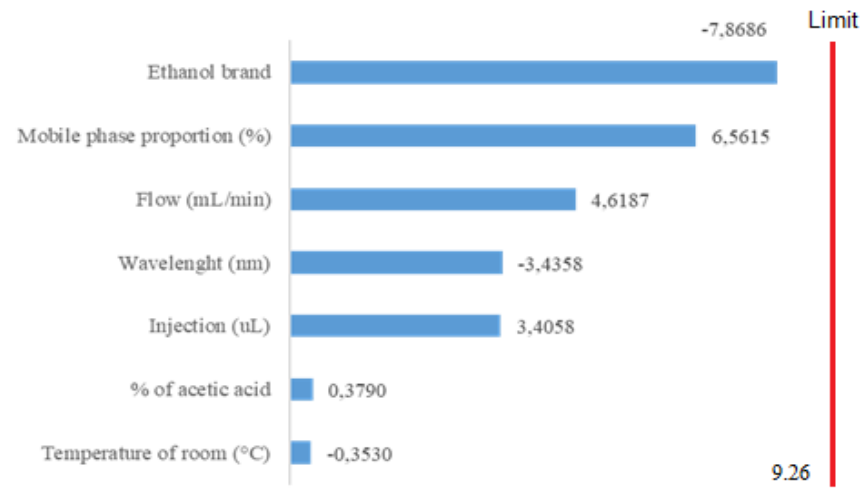

Figure 3. Effect of the variations studied in the parameter robustness by the Pareto graph.

\section{Selectivity}

Selectivity was evaluated by forced degradation procedure or stress test. The Figures 4 shows the comparison of the chromatograms obtained for DOX sample in the forced degradation procedure in acidic (A), alkaline (B), oxidative (C), neutral (D) and photolytic media (E). The Figure 5 shows the overlap of chromatograms of DOX standard and sample.

\section{Limits of detection and quantification}

The results of the LOD and LOQ were 1.08 and $3.27 \mu \mathrm{g} \mathrm{mL}$ ${ }^{1}$, respectively.

\section{Discussion}

\section{Linearity}

The equation of the line, determined by the method of least squares, was $y=5150.8 \mathrm{x}-7824.5$, with a correlation coefficient (r) greater than 0.9997 and the statistical data did not present significant linearity deviation a 5\% level of significance, presenting F calculated (0.21) lower than the F critical (3.26).

\section{Precision}

The results were analyzed by $\mathrm{RSD}(\%)$. The low RSD values $(0.5,2.35$ and $1.13 \%)$ confirm the precision of the method.

\section{Accuracy}

The mean percentage recoveries of the DOX tablets were found in accordance with the fixed limits of 98.0 to $102.0 \%$ (34).

\section{Robustness}

The robustness evaluation of the chromatographic method for DOX was performed using the method proposed by Youden e Steiner (36). Seven analytical parameters were selected and small variations were induced in the nominal conditions of the method. Then, eight runs were performed aiming to determine the influence of each parameter in the final result (37).

For the interpretation of the results, must to determine the influence of variations of each parameter in the final result, the mean of the four values corresponding to the upper case letters (normal working) was compared to the mean of the four values corresponding to the lower case letters (small changes), the final result is the effect value. The effect value is comparing it with the values obtained experimentally with the calculated effect should be analyzed. In this study the value of calculated effect was 9.26. Thus, the method was robust after the statistical evaluation of the results, where all the values referring to the calculated effects were lower, than allowing to occur small variations that may be recurrent in laboratory routines, but, with reliable results.

\section{Selectivity}

The overlay of the peaks obtained from forced degradation showed that is possible the method was able to identify the main peak with degradation. In addition, the method was selective, since the pharmaceutical tablets excipients do not influence the quantification of DOX.

\section{Limits of detection and quantification}

The values are low, which indicates the sensitivity of the method and the ability to detect and quantify DOX in tablets by the proposed method.

\section{Conclusions}

An analytical HPLC-UV method was developed and validated for the quantitative determination of DOX in tablets using a mixture of purified water $+0.5 \%$ acetic acid and ethanol $(40: 60, \mathrm{v} / \mathrm{v})$. The results indicated that the developed HPLC-UV method has been tested positively in the following subjects: linearity, precision, accuracy, robustness, selectivity, adequate detection and quantification limits. Its advantages over other existing method include lower generation of waste and damages for the environment and the operator. Finally, it is an alternative method, which can be ecologically correct and safe to be used in routine analyzes of quality control. 


\section{Acknowledgments}

The authors acknowledge FAPESP \#2015/21957-7 (São Paulo, Brazil), Capes (São Paulo, Brazil) and CNPq (Brasília, Brazil).

\section{Conflict of interest}

The authors declare no conflict of interest.

\section{References}

1. Garrido-Mesa, J., Algiere, F., Rodriguez-Nogales, A., Utrilla, M. P., Rodriguez-Cabezas, E. R., Zarzuelo, A., et al. A new therapeutic association to managerelapsing experimental colitis: Doxycycline plus Saccharomyces boulardii; Pharmacological Research 2015; 97:48-63.

2. Suaréz, D. F., Consuegra, J., Trajano, V. C., Gontijo, P. P. G. G., Cortés, M. E., Denadai, A. L., et al. Structural and thermodynamic characterization of doxycycline $/ \beta$ cyclodextrin supramolecular complex and its bacterial membrane interactions. Colloids and Surfaces B: Biointerfaces 2014; 118:194-201.

3. Pomorska-Mól, M., Kwit, K., Markowska-Daniel, I., Pejsak, Z. The effect of doxycycline treatment on the post vaccinal immune response in pigs. Toxicology and Applied Pharmacology 2004; 278:31-38.

4. Ramesh, P. J., Basavaiah, K., Tharpa, K., Vinay, K. B., Revanasiddappa, H. D. Development and validation of RP-HPLC method for the determination of doxycycline hyclate in spiked human urine and pharmaceuticals. Journal of Pre-Clinical and Clinical Research 2010; 4:101-107.

5. Ruiz, S. M. A., Olvera, L. G., Bernad, M. J. B., Chacón, S. C. C., Estrada, D. V. Comparative pharmacokinetics of a new oral long acting formulation of doxycycline hyclate: A canine clinical trial. European Journal of Pharmaceutical

2015;

80:9-15.

6. Kazakevich, Y.; Lobrutto, R. HPLC for Pharmaceutical Scientists, John Wiley \& Sons: New Jersey, 2007.

7. Rambla-Alegre, M.; Martí-Centelles, R.; EsteveRomero, J.; Carda-Broch, S. Application of a liquid chromatographic procedure for the analysis of penicillin antibiotics in biological fluids and pharmaceutical formulations using sodium dodecyl sulphate/propanol mobile phases and direct injection. Journal of Chromatography A 2011; 1218:4972-4981.

8. Dong, M. W. The Essence of Modern HPLC: Advantages, Limitations, Fundamentals, and Opportunities. LCGC Separation Science 2013; 31:472479.
9. Ruz, N.; Zabala, M.; Kramer, M.G.; Campanero, M.A.; Dios Viéitez, M.C.; Blanco-Príeo, M.J. Rapid and simple determination of doxycycline in serum by highperformance liquid chromatography: Application to particulate drug delivery systems. Journal of Chromatography A 2004; 1031:295-301.

10. Kogawa, A. C.; Salgado, H. R. N. Quantificaation of doxycycline hyclate in tablets by HPLC-UV Method. Journal of Chromatographic Science 2013; 51:919-925.

11. Hadad, G.; El-Gindy, A.; Mahmoud, W. HPLC and chemometrics-assisted UV-spectroscopy methods for the simultaneous determination of ambroxol and doxycycline in capsule. Spectrochimica Acta Part A: Molecular and Biomolecular Spectroscopy 2008; 70:655-663.

12. Šatínský, D.; Santos, L.M.L; Sklenářová, H.; Solich, P.; Montenegro, C.M.B.S.M.; Araújo, A.N. Sequential injection chromatographic determination of ambroxol hydrochloride and doxycycline in pharmaceutical preparations. Talanta 2005; 68:214-218.

13. Skúsalon, S.; Ingóelfsson, E.; Kristmundsdóttir, T. Development of a simple HPLC method for separation of doxycycline and its degradation products. Journal of Pharmaceutical and Biomedical Analysis 2003; 33:667672.

14. Kogawa, A.C.; Salgado, H.R.N. Comparative study over methods developed for quantification of darunavir in tablets by environmental friendly infrared and capillary electrophoresis techniques. Journal of International Research in Medical and Pharmaceutical Sciences 2015; 2:99-105.

15. de Marco, B.A.; Rechelo, B.S.; Tótoli, E.G.; Kogawa, A.C.; Salgado, H.R.N. Evolution of green chemistry and its multidimensional impacts: A review. Saudi Pharm J DOI

10.1016/j.jsps.2018.07.011

16. Kogawa, A.C.; Salgado, H.R.N. Analytical Methods: Where do we stand in the current environmental scenario? EC Microbiology 2017; 13:102-104.

17. Kogawa, A.C.; Salgado, H.R.N. Analytical methods need optimization to get innovative and continuous processes for future pharmaceuticals. Scholars Academic Journal of Pharmacy 2016; 5:240-244.

18. Marco, B.A., Salgado, H.R.N. Development and validation of a green RP-HPLC method for quantification of cefadroxil capsules. World Journal of Pharmacy and Pharmaceutical Science 2017; 6:20742091.

19. Wirz, K.C.; Studer, M.; Straub, J.O. Environmental risk assessment for excipients from galenical pharmaceutical 
production in wastewater and receiving water. Sustainable Chemistry and Pharmacy 2015; 1:28-35.

20. Rodrigues, D.F.; Salgado, H.R.N. Development and validation of a green analytical method of rp-hplc for quantification of cefepime hydrochloride in pharmaceutical dosage form: simple, sensitive and economic. Current Pharmaceutical Analysis 2016; 12:306-314.

21. Trindade, M.T.; Salgado, H.R.N. Development and validation of a modern and stability-indicating method for the quantification of ceftriaxona sodium in powder for injection by infrared spectroscopy. Physical Chemistry 2017; 7:55-62.

22. Marco, B.A; Salgado, H.R.N. Development and validation of a green RP-HPLC method for quantification of cefadroxil capsules. World Journal of Pharmacy and Pharmaceutical Sciences 2017; 6:20742091.

23. Tótoli, E.G.; Salgado, H.R.N. Development, optimization, and validation of a green and stabilityindicating HPLC method for determination of daptomycin in lyophilized powder. Journal AOAC International 2015; 98:1276-1285.

24. Tótoli, E.G.; Salgado, H.R.N. Development and validation of an economic, environmental friendly and stability-indicating analytical method for determination of ampicillin sodium for injection by RP-HPLC. World Journal of Pharmacy and Pharmaceutical Sciences 2014; 3:1928-1943.

25. Rechelo, B. S.; Fernandes, F.H.A.; Kogawa, A.C.; Salgado, H.R.N. New environmentally friendly method for quantification of cefazolin sodium. European Chemical Bulletin 2018; 6:238-245.

26. Figueiredo, A.L.; Kogawa, A.C.; Salgado, H.R.N. Development and validation of an ecological, new and rapid stability-indicating High Performance Liquid Chromatographic method for quantitative determination of aztreonam in lyophilized powder for injection. Drug Anal Res 2017; 1:24-30.

27. Kogawa, A.C.; Salgado, H.R.N. Rifaximin stability: a look at UV, IR, HPLC, and turbidimetry methods. J AOAC Int 2018; 101:410-413.
28. ICH. International Conference on Harmonization. Validation of analytical procedures: text and methodology Q2(R1), 2005.

29. INMETRO. Instituto Nacional de Metodologia de Metrologia, Normalização e Qualidade Industrial. Orientação sobre validação de métodos de ensaios químicos, DOQ-CGCRE-008, 2007.

30. ISO. International Organization for Standardization. General Requirements for the Competence of Testing and Calibration Laboratories, ISSO/IEC 17025, 1999.

31. BRASIL. Agência Nacional de Vigilância Sanitária (ANVISA). RDC 166, July 24th 2017. Dispõe sobre a validação de métodos analíticos e dá outras providências. Diário Oficial da União. Brasília, 25 Jul. 2017.

32. ICH. International Conference on Harmonizaion. Validation of Analytical Procedures: Methodology Q2B,

1996.

33. Brasil, Agência Nacional de Vigilância Sanitária, RE 899, Guia para validação de métodos analíticos e bioanalíticos, Brasília, 2003.

34. AOAC. Association of Official Analytical Chemists. Official Methods of Analysis. 17. ed. Gaithesburg: AOAC,

2002.

35. Kogawa, A.C.; Salgado, H.R.N. Impurities and Forced Degradation Studies: A Review. Curr Pharm Anal 2016; 12:18-24.

36. Youden, W.J.; Steiner, E.H. Statistical Manual of AOAC - Association of Official Analytical Chemistry. Washington: AOAC,

1975.

37. César, I.C.; Pianettii, G.A. Robustness evaluation of the chromatographic method for the quantification of lumefantrine using Youden's test. Brazilian Journal of Pharmaceutical Sciences 2009; 45:1-6. 